\title{
Breakdown of Kidney and Ureteral Stones Using Extracorporeal Shock Wave Lithotripsy in Zakho City
}

\author{
Shamoo K. Al-Hakary \\ Department of Physics, Faculty of Science, University of Zakho, Zakho, Iraq \\ Email: shamookhudaida@yahoo.com
}

Received 6 April 2015; accepted 8 June 2015; published 11 June 2015

Copyright (C) 2015 by author and Scientific Research Publishing Inc.

This work is licensed under the Creative Commons Attribution International License (CC BY). http://creativecommons.org/licenses/by/4.0/

(c) (i) Open Access

\section{Abstract}

In the present study, investigation of extracorporeal shock wave lithotripsy in Zakho City for breakdown kidney and ureteral stones has been carried out. The data were collected from the center of breakdown kidney stones in Zakho hospital. A total of 34 patients ( 25 male and 9 female) of ages ranged from 20 - 60 years were treated with ESWL. The patient harboring 24 renal stones and 10 ureteral stones of size ranged from 7 to $23 \mathrm{~mm}$ of almost patients are $8 \mathrm{~mm}$ and composed of calcium oxalate. The study has been conducted taking in to consideration the parameters (type, sizes, composition and location of stone as well as region and ages of patients, also power, number of shock wave and session). The results show that the number of shock wave decreases nearly exponentially with the ages of patients for calcium oxalate stone of size $8 \mathrm{~mm}$ under constant power 4 watt while it tends to increase according to increasing stones size for the patients of ages 20 - 30 years. The size of calcium oxalate stones decreases nearly exponentially with the patients' ages for workers in Zakho city. Also for same size $8 \mathrm{~mm}$ of (calcium, phosphate, and oxalate) stones and different regions of zakho city, the number of shock waves decreases according to increasing ages of patients. Contrary to that for certain size of stones $8 \mathrm{~mm}$, the number of shock wave starts to increase from uric acid to maximum value for calcium oxalate stone for the adult patients of age's 22 up to 30 years. However for elders ages 30 - 60 years and different regions, the size of renal and ureteric stones increases from the minimum value for calcium, phosphate, oxalate to maximum value for calcium oxalate stone only. Uric acid stone requires minimum power to break, while the calcium oxalate needs maximum power to fragment due to its hardness composition. Later number of session of shock wave required for crushing each stones size increases according to increasing its size while its variation due to enhancing patients ages for calcium oxalate of size $8 \mathrm{~mm}$ results in nearly a decreasing exponential behavior.

\section{Keywords}

Shockwave Lithotripsy, Kidney and Ureteral Stones, Stone Size, Stone Composition, Adults, Elderly, 


\section{Patient Ages}

\section{Introduction}

Extracorporeal shock wave lithotripsy (ESWL) is revolutionizing the treatment of kidney stones. This technology, which disintegrates stones in the kidney and other upper urinary areas through the use of shock waves, does not require an incision and is immensely attractive to patients who suffer from such stones [1]. Also shock wave lithotripsy (SWL) is a common and effective clinical method to comminute kidney stones [2]. On the other hand, it is a treatment of choice for most patients with upper urinary tract calculi. Nevertheless, clearance of the generated fragments is not immediate and a significant number of patients have been reported to have residual fragments [3]. The first use of (ESWL) to destroy kidney stones was in 1980. Within a few years, it became a standard for treatment for renal stones. Shock wave lithotripsy of gallstones began in 1985 [4]. This technique is the most common treatment for kidney stone disease. The idea of this non-invasive procedure is to generate high intensity pressure waves (shock waves) outside the patient and to focus them on the stone to fragment it [5]. The assessment of the therapeutic efficiency, complications and limitations of (ESWL) in urolithiasis in the initial experience using a third generation electromagnetic lithotripter was done by [6]. However, the application of (ESWT) in musculoskeletal disorders has been around for more than a decade and is primarily used in the treatment of sports related over-use tendinopathies such as proximal plantar fasciitis of the heel, lateral epicondylitis of the elbow, calcific or non-calcific tendonitis of the shoulder and patellar tendinopathy. [7] [8] define factors that have a significant impact on the stone-free rate after ESWL. Three variables were significantly affecting the success rate namely stone size, number of shock waves and location of stone. [9] have shown that there are no statistically significant correlation between the number of treatments and localization of stones in the ureter, as well as a statistically significant correlation between the size of the stone and the localization of calculus in the ureter. [10] perform (ESWL) of pancreatic stones in eight patients with chronic pancreatitis and a dilated duct system harboring stones 5 to $20 \mathrm{~mm}(3 \times 10$ (SD) $5 \mathrm{~mm})$ in diameter. After endoscopic sphincterotomy of the pancreatic orifice, the stones are disintegrated by shock waves under fluoroscopic control using a kidney lithotripter (Dornier HM3).

The present study reports the results of application of (ESWL) in 34 patients (25 male and 9 female) with renal stones 24 in the left and right kidney and 10 in the ureter. The data were collected from patient's outcome to the centers of kidney stones breakdown in Zakho hospital, Kurdistan region north of Iraq and taking into consideration the parameters, shock wave number and its power, size, composition, location of stones as well as ages and region of patients to study the physical relations between them.

\section{Materials and Method}

From July 2013 to January 2015, a total of 34 patients (25 male and 9 female) harboring renal or ureteral stones, all patients of ages ranged from 20 - 60 years underwent extracorporeal shock wave lithotropsy. The localization of ureter and renal stones was specified for all patients before treatment through the plan X-ray KUB as well as stones size which are ranged from $7-23 \mathrm{~mm}$ was determined by measuring the longest diameter on (kidney, ureter and bladder [KUB]) for opaque stone. Plan abdominal film taken routinely to evaluate radio-opacity and stone size [11]. The stones lost on follow up, were analyzed in (Dr. Shaker Medical Laboratory in Zakho city) using Renal Stone Analysis. Almost analyzed Zakho stones composed of calcium oxalate with several others cystine, phosphate, Calcium phosphate, Struvite, cystine, and uric acid. ESWL treatment is performed on the machine Siemens Model Lithostar Multiline, Nixdorf and Modular RLX2-120.034.06 of the following properties: Operating voltage $104.4 \mathrm{kv}$, Current $4.2 \mathrm{~mA}$ and power ranged from $(0.1$ - 9) watt, which has a combined ultrasonographic and fluoroscopic display, large energy density in order to obtain optimum focus (without damaging surrounding tissue) and minimal pain that on rare occasions requires for mild sedation-sedation. Number of maximum shock waves used by one ESWL treatment is 4000, while the energy was dependent on stones localization. Our appliance, like most modern appliances used electromagnetic source. The shock waves are transmits to the body through the water, focused by acoustic lens system so that the released energy is reflected on the surface of the stone, see Figure 1. Treatment session consist of 3000 shock waves during time interval (20 - 30) Minutes, all procedures were performed under analgesia. 


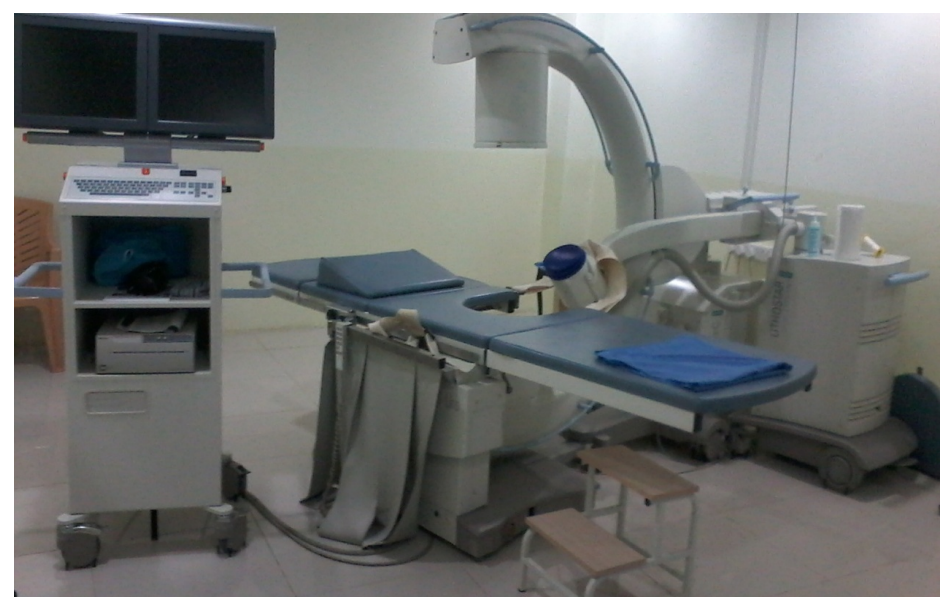

Figure 1. Extracorporeal shock wave lithotripsy in Zakho hospital.

\section{Results and Discussion}

European treatment guidelines advise active ESWL treatment for all stones larger than 6 - 7 mm [12]. Factors known to alter the extracorporeal lithotripsy outcome are: stone size, location, chemistry, number as well as patient anatomy. The present work was carried out to study the physical relation between the parameters of a total number of patients 34 male and female. The data were collected between the periods July 2013 to January 2015 from centers of kidney stones breakdown in Zakho hospital after treatment with (ESWL). Age of the patients ranged from 20 to 60 years harboring renal or ureteral stones. Size of stones ranged from $7 \mathrm{~mm}$ to $23 \mathrm{~mm}$ of compassion (cystine, Struvite, Calcium phosphate, uric acid and calcium oxalate). A number of shock waves were needed to breakdown the stones reached to 18,000 with 6 session and power 5 watt for calcium oxalate stone of size $23 \mathrm{~mm}$. This indication is well agreement with the previous studies states that the stones larger than $15 \mathrm{~mm}$ and calcium oxalate monohydrate stones usually require several ESWL procedures for clearance. Uric acid, calcium oxalates dehydrate as well as struvite stones are much easier to be disintegrated. ESWL has poor results for stones located in the lower calyx ("stone free" rate of 41 - 70) [13]-[16]. In order to explain physically the parameters that affect the extracorporeal lithotripsy outcome such as stone size, location, chemistry, patient's ages well as patient's region, the relation represents between them graphically. Figure 2 illustrated the decreasing exponential behavior between the number of shock wave and patient's ages for calcium oxalate in Zakho region under constant power 4 watt. This indicates that the calcium oxalate of adult's patients is more stiffness than the elders' patients.

Contrary to that the number of shock wave increases with the size of stone for the same composition for adult's patients of ages 20 - 30 years (male and female) under same power 4 watt, Figure 3 . Because there was a significant positive correlation between stone size and number of treatments in the total sample, respectively, as the stones was larger needed higher number of treatments [9]. Contrary to that interesting results are presented by Tarawneh and colleagues, who proved an inverse correlation between the performance of ESWL and size of the stone [17].

On the other hand, for the same composition and for workers at Zakho region it is found that the size of stones decrease nearly exponentially with the patient ages as shown in Figure 4. This is attributed to the continuous work of patients and drinking more water and others liquid during the work, this means that almost of calcium oxalate lost from human body during the live. Also for (calcium, phosphate, oxalate) stone, we obtained the same decreasing exponential behavior between the number of shock wave and the patient age for size stone $8 \mathrm{~mm}$ and appointed patients due to the same reasons, Figure 5.

Number of shack wave versus type of stones (composition), renal and ureter of size $8 \mathrm{~mm}$ for elders patients are plotted in Figure 6. It appears from figure that the stones that are chemically softer required significantly fewer applications of ESWL, regardless of its size [18]. Recent studies and experience have shown that the composition of stone certainly affects the effectiveness of ESWL. It is shown that not all stones are equally sensitive to treatment. The composition of the stone, which determines its strength, also has an impact on its dissolution, breaking with ESWL and elimination after the treatment. 


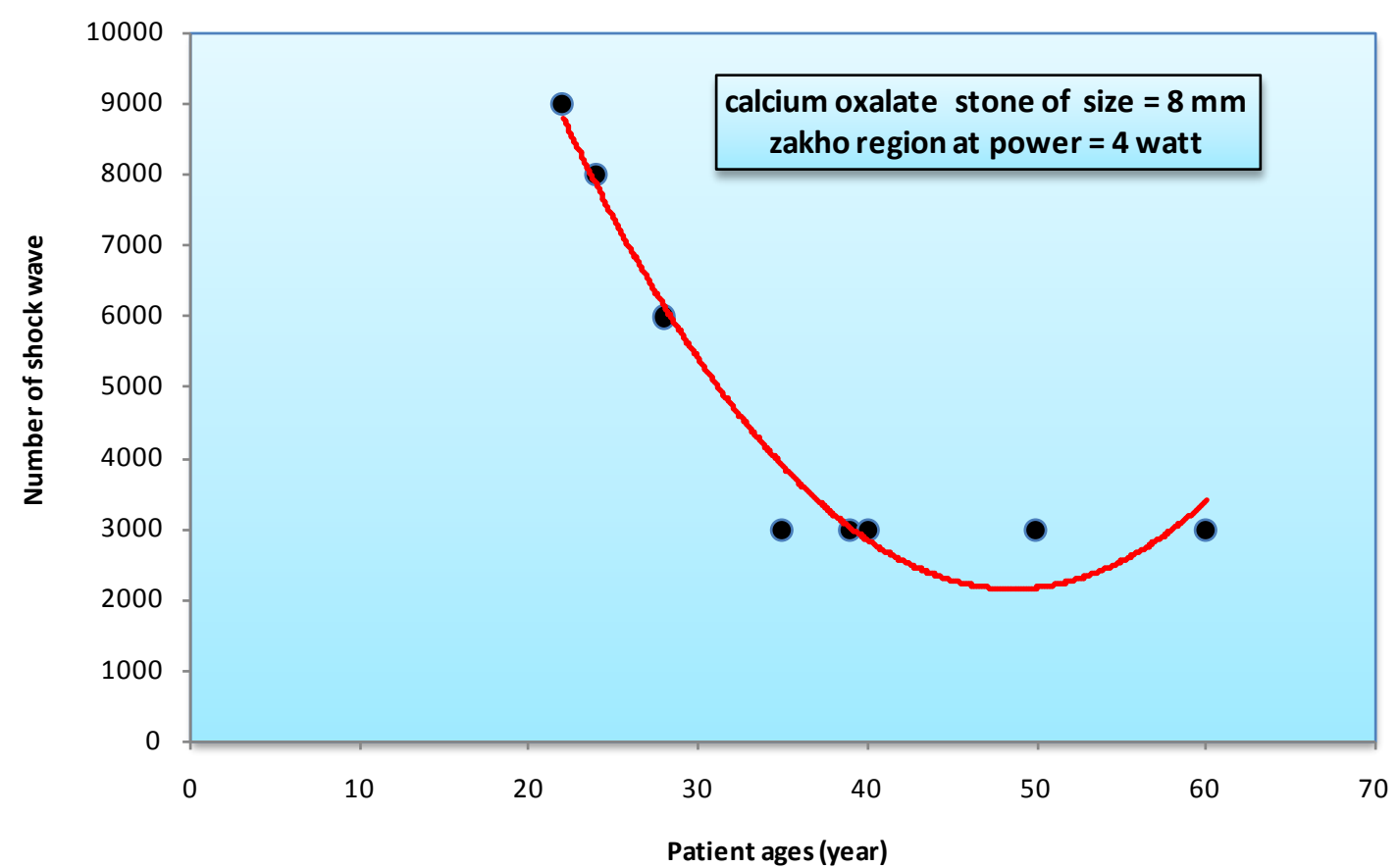

Figure 2. Number of shock wave as a function of patient ages.

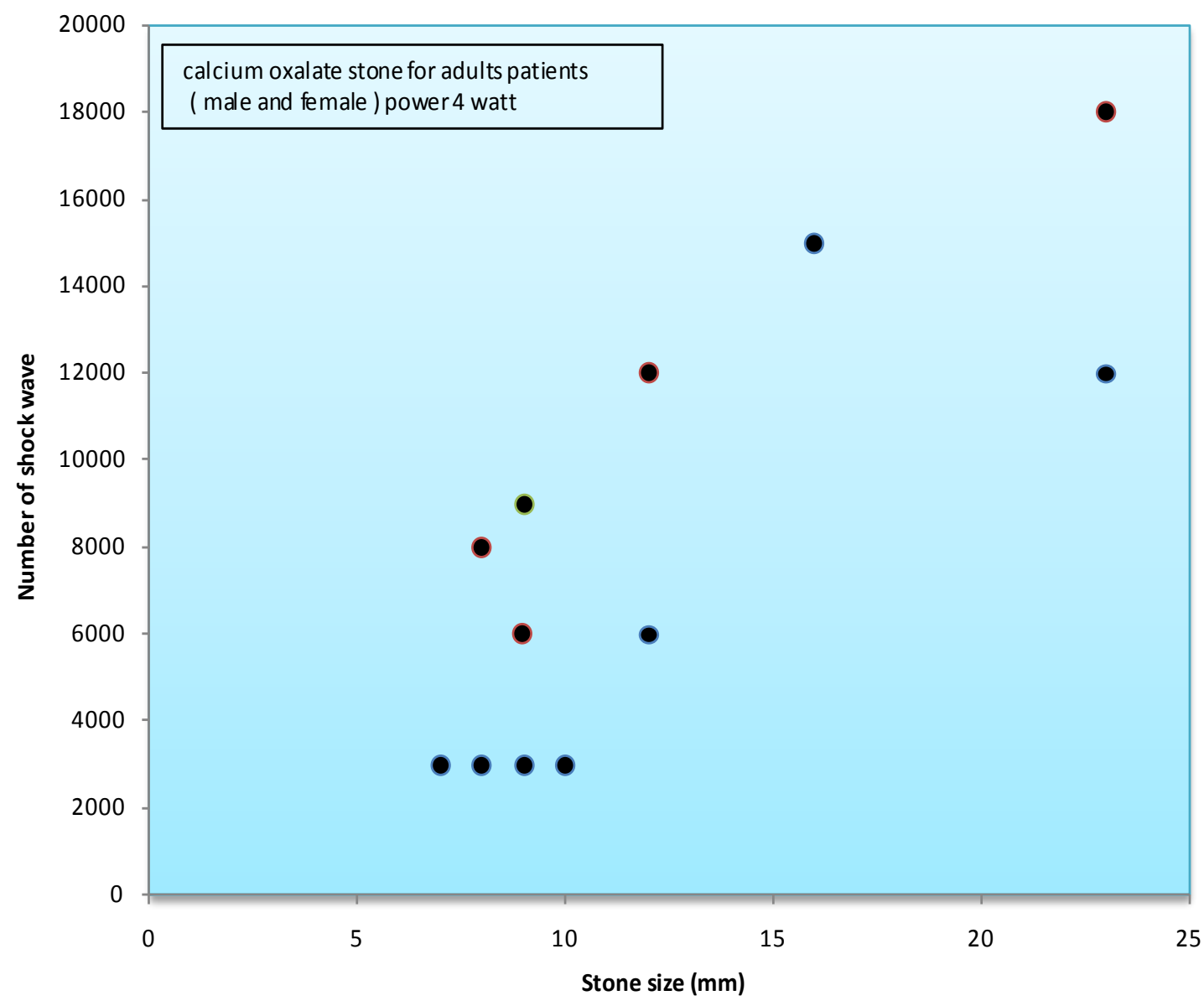

Figure 3. Number of shock wave versus stone size. 


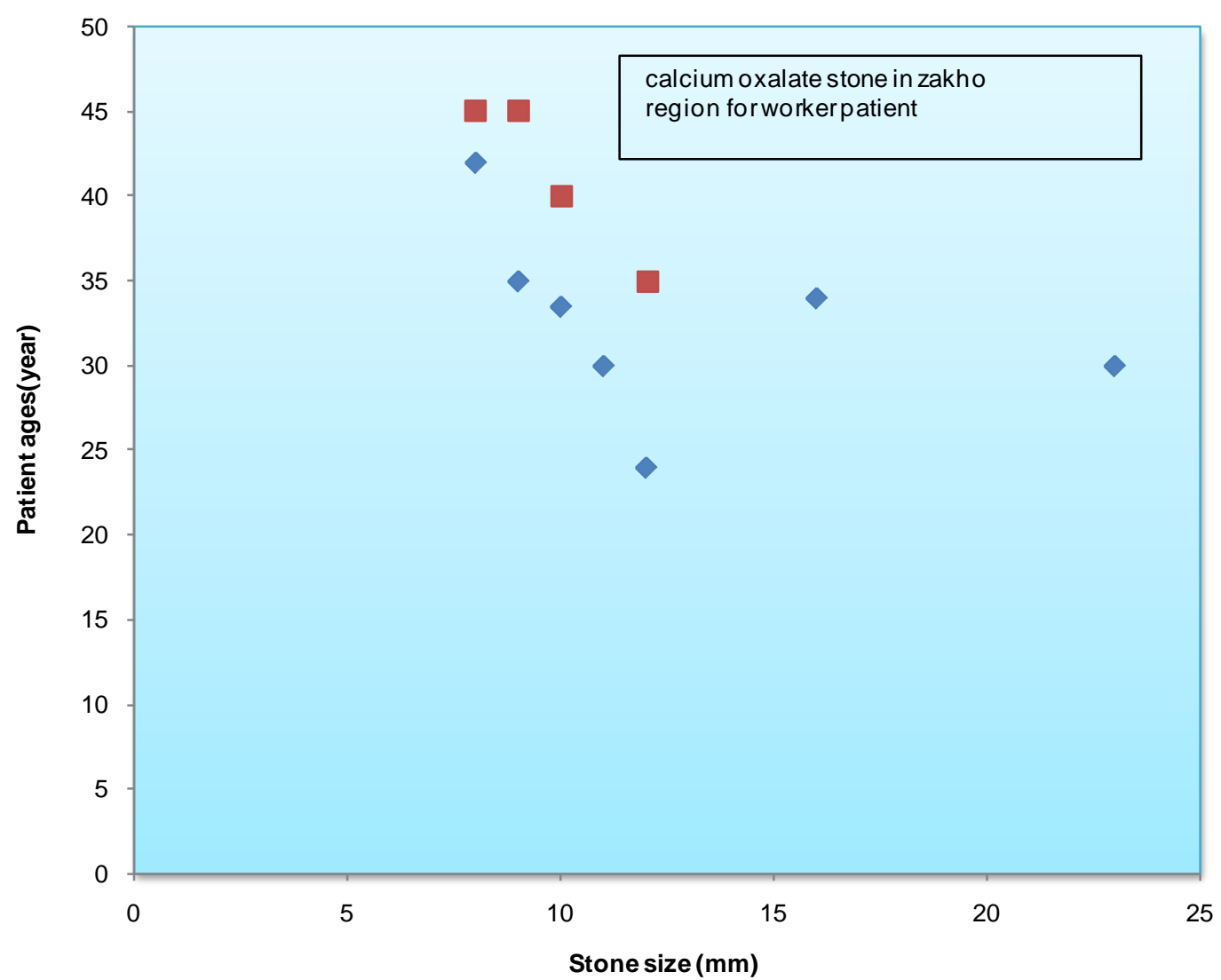

Figure 4. Patient ages as a function of stone size.

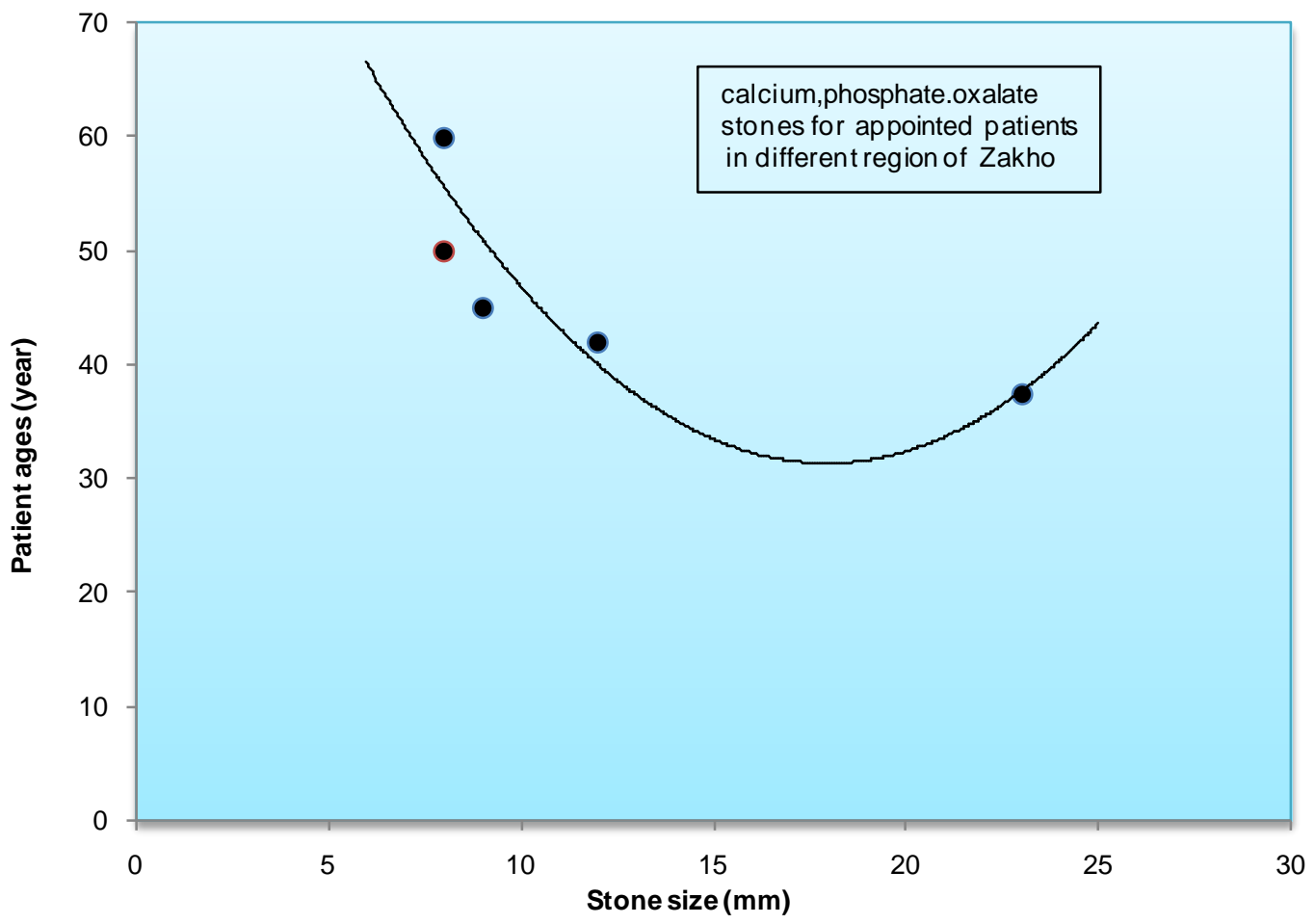

Figure 5. Patients ages as a function of stone size. 
As well as type of stones versus stone size for the ages 31 - 60 years (elders), reveals the increasing relation starting from the minimum value for both (phosphate calcium oxalate and oxalate) stones to maximum value for (calcium oxalate) stone as shown in Figure 7.

Another remarkable result of the present research is the (ESWL) power needed for each type of stone to crush in to fragments, Figure 8 represent the variation of the (ESWL) power with the type of stone for $8 \mathrm{~mm}$ size and

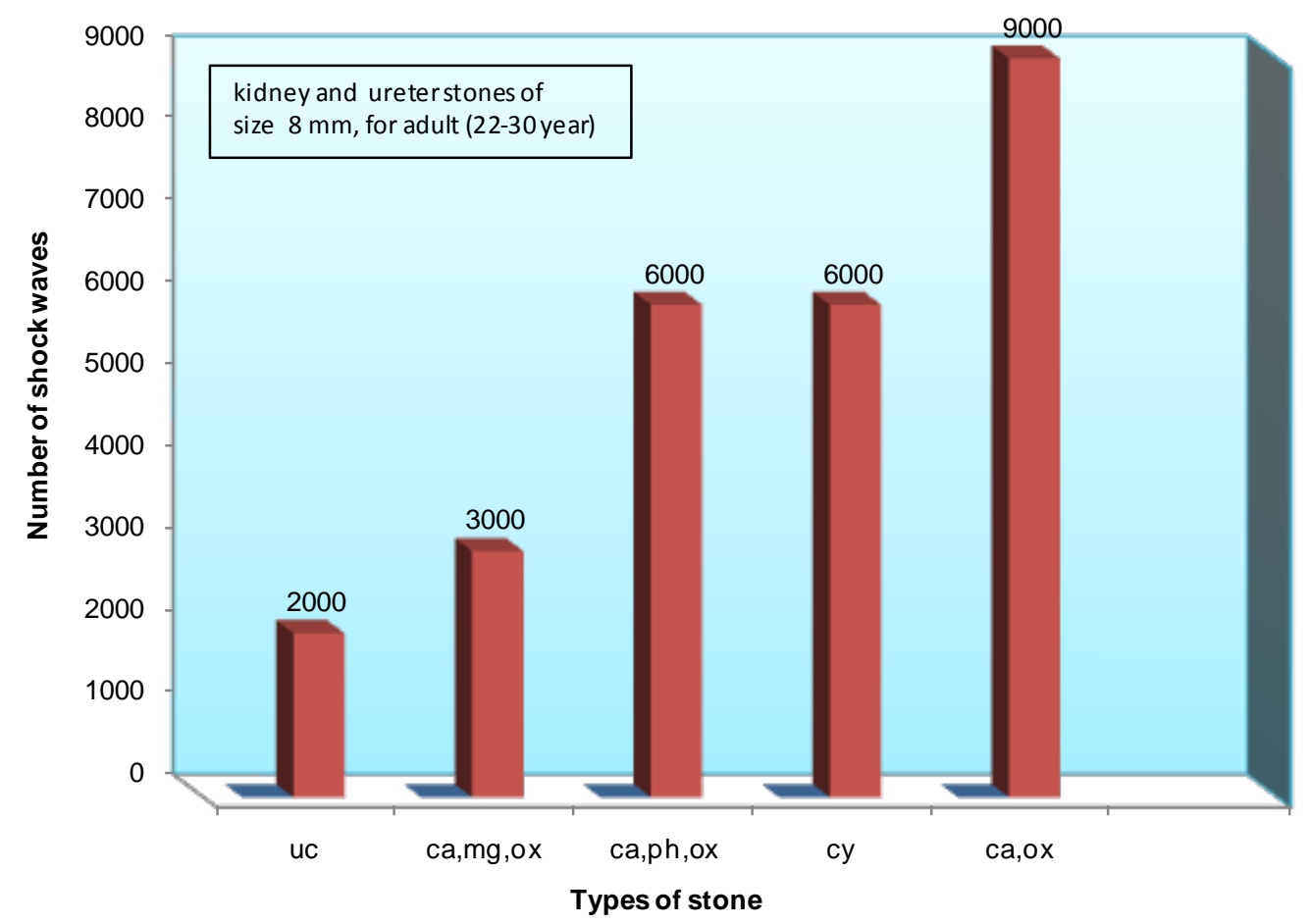

Figure 6. Number of shock waves versus types stone.

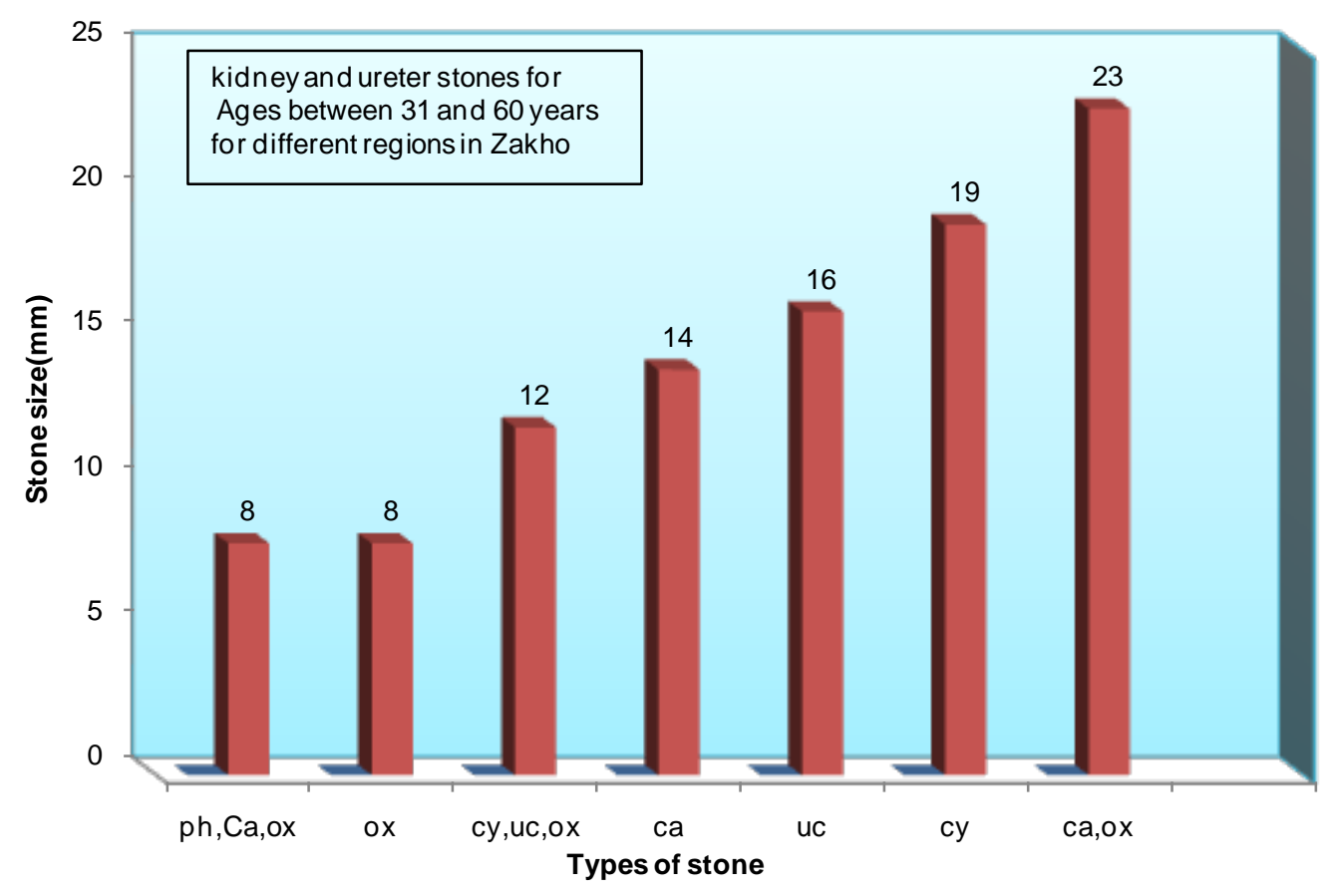

Figure 7. Stone size as a function of the stone types. 
different ages of patients. It is clear from the chart diagram that the uric acid stone required the minimum power to break, while the calcium oxalate needs maximum power to fragment due to its hardness composition.

Also another important result of the present study is the number of session of shock wave required for crushing each stones size shown in increasing curve Figure 9. Because large stones which will require several ESWL sessions and consequently increase the number of shock wave are best treated with percutaneous nephrolithotomy plus (ESWL) [19], later we plot the number of sessions against the patient's ages for calcium oxalate of size $8 \mathrm{~mm}$ results nearly a decreasing exponential behavior, Figure 10. Because patient age was a significant predicting factor affecting the treatment outcome of ESWL for renal, but not ureteric stones [20]. This could be attributed to the fragmentation difficulty of these compositions due to their hardness for adults patients, and easier for elders patients consequently, decreasing number of sessions.

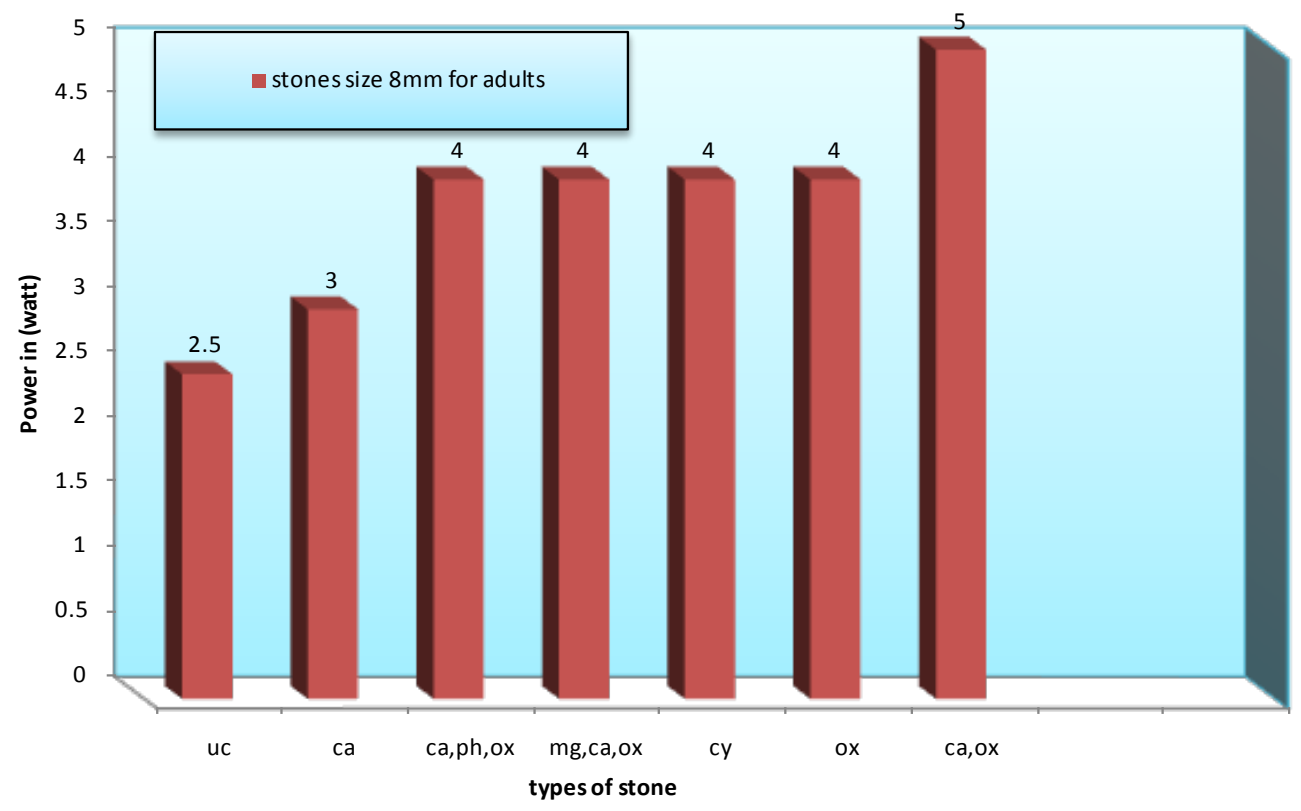

Figure 8. Power as a function of stone types.

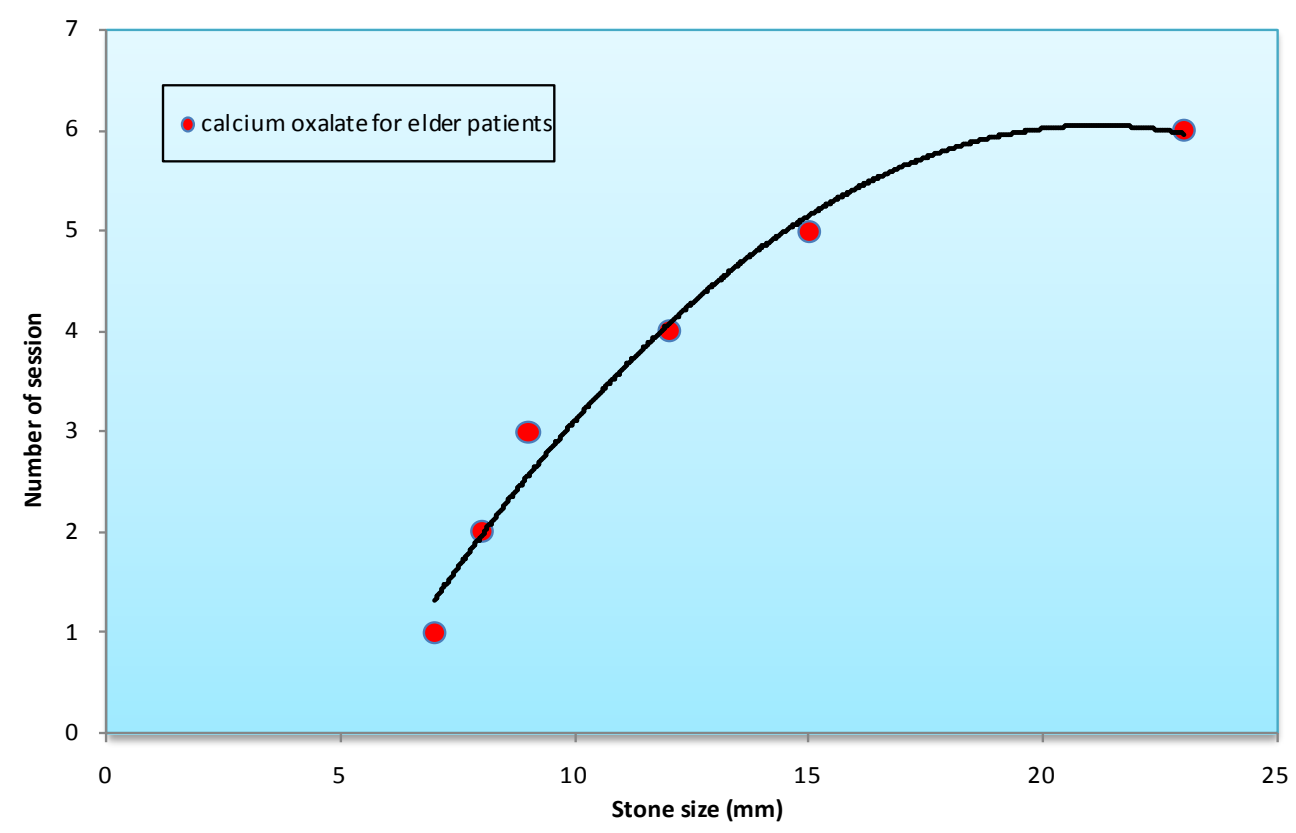

Figure 9. Number of session as a function of stone size. 


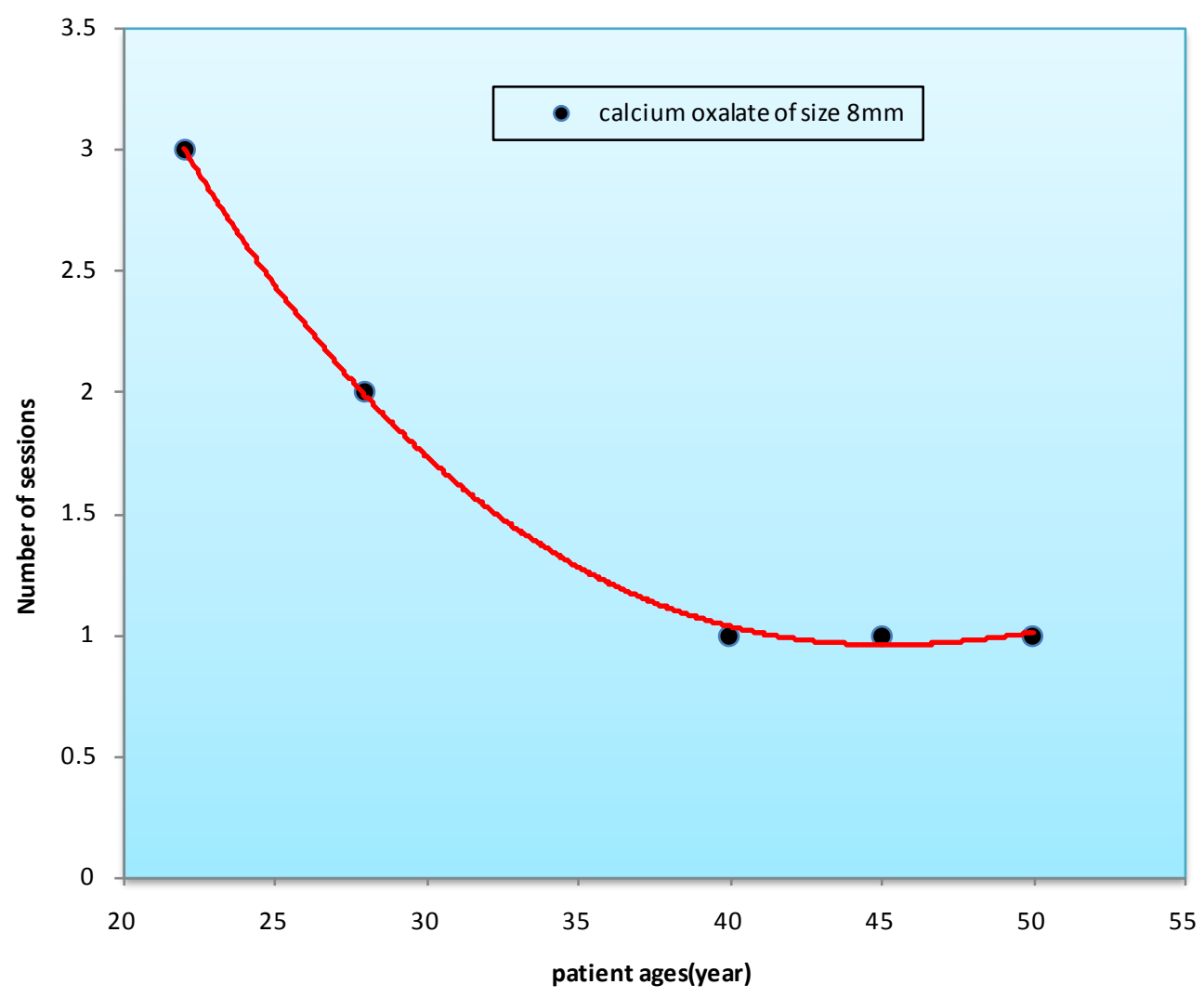

Figure 10. Number of session versus patient ages (year).

\section{Conclusion}

ESWL can be safely recommended for patients of urolithiasis irrespective of age and stone size with promising results of stone clearance and patient acceptance. It is a very effective modality for treatment of renal and ureteric stones which can be performed in outpatient basis. The success rate depends upon size, type and location of stone. As stone size increases, the success rate decreases. Also the success rate is better in ureteric stone compared to renal stone. The factors that influence the treatment outcome of this technique for renal and ureteral stones as a results of the present work, are patients ages, type, size and location of stones have a significant effect on the results of ESWL. Further studies are needed to identify possible explanations for this observation. Based on the results of this study, it is evidence that almost patients harbor calcium oxalate stones of size $8 \mathrm{~mm}$. This indicates that the patients begin to feel the pain at this size of stones within the ureter due to blocking the urea, as well as smaller size can pass through the ureter without pain. There is a significant positive correlation between the stone size and the number of treatments in the total sample, as well as decreasing exponential behavior between the number of shock wave and patients' ages for calcium oxalate in Zakho region. Uric acid stone requires minimum power to break, while calcium oxalate needs maximum power to fragment due to its hardness composition. The number of sessions against the patient's ages for calcium oxalate of size $8 \mathrm{~mm}$ results in nearly a decreasing exponential behavior because patient age is a significant predicting factor affecting the treatment outcome of ESWL for renal and ureteric stones.

\section{References}

[1] Herdman, R.C. (1984) Effects of Federal “Policies on Extracorporeal Shock Wave Lithotripsy” Is Case Study 36 in OTA’S Health Technology Case Study Series. OTA Health and Life Sciences Division.

[2] Lingeman, J.E. (1997) Urologic Clinics of North America, 24, 185-211.

[3] Costa-Bauzá, A., Perelló, J., Isern, B. and Grases, F. (2005) Urological Research, 33, 51-56. http://dx.doi.org/10.1016/S0094-0143(05)70363-3 
[4] Hossain, M.J., Uddin, M.N. and Islam, M.S. (2009) CMCTA, 20, 45-49.

[5] Weinberg, K. and Ortiz, M. (2009) Biomechanics and Modeling in Mechanobiology, 8, 285-299. http://dx.doi.org/10.1007/s10237-008-0135-0

[6] Tomescu, P., Pănuş, A., Mitroi, G., Drăgoescu, O., Stoica, L., Dena, S. and Enache, M. (2009) Current Health Sciences Journal, 35.

[7] Wang, C.-J. (2012) Surgery and Research, 7, 11. http://dx.doi.org/10.1186/1749-799X-7-11

[8] Abid, A.F. (2014) Open Journal of Urology, 4, 26-32. http://dx.doi.org/10.4236/oju.2014.43005

[9] Junuzovic, D., Prstojevic, J.K., Hasanbegovic, M. and Lepara, Z. (2014) Acta Informatica Medica, 22, 309-314. http://dx.doi.org/10.5455/aim.2014.22.309-314

[10] Sauerbruch, T., Holi, J., Sackmann, M. and Paumgartner, G. (2015) Extracorporeal Shock Wave Lithotripsy of Pancreatic Stones. http://gut.bmj.com/

[11] Gallagher, H.J. and Tolley, D.A. (2000) Current Opinion in Urology, 10, 551-555. http://dx.doi.org/10.1097/00042307-200011000-00003

[12] Grasso, M., Hsu, J. and Spaliviero, M. (2008) Extracorporeal Shockwave Lithotripsy. eMedicine by WebMD.

[13] Manu, R. (1998) Litotripsia extracorporeală cu unde de şoc (ESWL). în Urologie Clinică, Editura Medicală Amaltea, Bucureşti, 162-164.

[14] Tiselius, H.G., Ackermann, D., Alken, P., Buck, C., Conort, P. and Galluci, M. (2001) European Urology, 40, 362-371. http://dx.doi.org/10.1159/000049803

[15] Yang, H.S., Park, K.S. and Min, B.K. (1993) Korean Journal of Urology, 34, 109-115.

[16] Argyropoulus, A.N. and Tolley, D.A. (2007) European Urology, 52, 344-350. http://dx.doi.org/10.1016/j.eururo.2007.04.066

[17] Tarawneh, E., Awad, Z., Hani, A., Haroun, A.A., Hadidy, A., Mahafza, W., et al. (2010) Saudi Journal of Kidney Diseases and Transplantation, 21, 660-665.

[18] Kovacevic-Prstojevic, J. (2014) Broj vantjelesnih razbijanja kamenaca u odnosu na veličinu kamenca, njegovu lokalizaciju u urinarnom traktu, temorfološku strukturu kamenca. Magistarski rad. Medicinski fakultet Univerziteta u Sarajevu, Sarajevo.

[19] Salam, M.S. (2003) Principle and Practice of Urology. Brown Walker Press, Boca Raton, 721.

[20] Ng, C.-F., Wong, A. and Tolley, D. (2007) BJU International, 100, 392-395. 